\title{
Preparation and Performance of Vanadium Tailings-Reservoir Sediment-Phosphogypsum-Based Foamed Concrete
}

\author{
Xiaowei Cui, ${ }^{1}$ Yanqing Di, ${ }^{1}$ Changlong Wang ${ }^{10},{ }^{1,2}$ Yongbo Wang, ${ }^{3}$ Suhua Zhang, ${ }^{3}$ \\ Yuxin Zhai, ${ }^{4}$ Yongchao Zheng, ${ }^{5}$ Shaoxi Wang, ${ }^{2} \mathrm{Xin} \mathrm{Li}^{2}{ }^{2}$ Jingliang Chen, ${ }^{2}$ and Zhenzhen Ren ${ }^{2}$ \\ ${ }^{1}$ Shaanxi Key Laboratory of Comprehensive Utilization of Tailings Resources, Shangluo University, Shangluo 726000, China \\ ${ }^{2}$ School of Civil Engineering, Hebei University of Engineering, Handan 056038, China \\ ${ }^{3}$ Handan Jianye Construction Engineering Quality Inspection Co., Ltd., Handan 056000, China \\ ${ }^{4}$ China Railway Construction Group Co., Ltd., Beijing 100040, China \\ ${ }^{5}$ State Key Laboratory of Solid Waste Reuse for Building Materials, Beijing Building Materials Academy of Science Research, \\ Beijing 100041, China
}

Correspondence should be addressed to Changlong Wang; wangchanglong@hebeu.edu.cn

Received 16 September 2021; Revised 13 October 2021; Accepted 19 October 2021; Published 1 November 2021

Academic Editor: Gengxin Sun

Copyright (C) 2021 Xiaowei Cui et al. This is an open access article distributed under the Creative Commons Attribution License, which permits unrestricted use, distribution, and reproduction in any medium, provided the original work is properly cited.

Foamed concrete (FC) was prepared from raw materials of vanadium tailings (VTs), reservoir sediment (RS), and phosphogypsum (PG). The physicochemical properties of the raw materials were studied by using X-ray diffraction (XRD), X-ray fluorescence (XRF) analysis, and inductively coupled plasma emission spectrometer (ICP-OES). The preparation and properties of FC were investigated by particle size analysis and strength test. The hydration products and microstructure of FC were analyzed by XRD and field emission scanning electron microscopy (FE-SEM). The results show that when the specific surface area (SSA) of VTs is $768 \mathrm{~m}^{2} \cdot \mathrm{kg}^{-1}$ and the content is $40 \%$, the products with a compressive strength of $3.56 \mathrm{MPa}$ and density of $619.1 \mathrm{~kg} \cdot \mathrm{m}^{-3} \mathrm{meet}$ the requirements of JG/T 266-2011 standard on FC of grades A06 and C3.0; the main mineral phases in the products are calcium silicate hydrate (C-S-H) gel, ettringite (AFt), and calcite, as well as the residual mineral phases after the system reaction include quartz, orthoclase, mullite, pyrite, and PG.

\section{Introduction}

Vanadium tailings (VTs) are the tailings produced as the metal vanadium is extracted from stone coal through crushing, calcination, and leaching. VTs mainly encompass $\mathrm{SiO}_{2}$ and a small amount of $\mathrm{Al}_{2} \mathrm{O}_{3}$ [1-3]. The production of every $1 \mathrm{t}$ of $\mathrm{V}_{2} \mathrm{O}_{5}$ from stone coal would generate $150 \mathrm{t}$ of VTs. Usually, VTs are treated by tailings dam stacking in the concentrator. The chemical components of VTs and residual beneficiation reagents produce serious damage to the ecological environment, especially the VTs containing heavy metals, whose loss will harm the whole ecological environment to the people. The accumulation of large quantities of VTs brings economic, environmental, and health problems to many countries [4].

The recycling of tailings is an effective way for mining enterprises to increase economic benefits and improve the eco-environment. Lu et al. and Wang et al. $[5,6]$ demonstrated that, after being grinded into ultrafine powders, the $\mathrm{SiO}_{2}$-rich tailings can actively react with alkaline compounds like $\mathrm{Ca}(\mathrm{OH})_{2}$; the active $\mathrm{SiO}_{2}$ and $\mathrm{Al}_{2} \mathrm{O}_{3}$ can react with $\mathrm{Ca}(\mathrm{OH})_{2}$ and $\mathrm{CaSO}_{4}$ to produce calcium silicate hydrate (C$\mathrm{S}-\mathrm{H})$ gel, calcium aluminate hydrate $(\mathrm{C}-\mathrm{A}-\mathrm{H})$, or ettringite (AFt). Therefore, it is feasible to take tailings as the siliceous raw material for the preparation of building materials $[7,8]$.

Reservoirs are hydraulic engineering structures that regulate water flow and resist floods and droughts. To a certain extent, a reservoir can change the transfer and exchange of material and energy between water bodies. Under the effects of the landform and hydrodynamics of the reservoir, the sediment is gradually deposited at the bottom. If conditions allowed, the sediment will release a large amount of organic matter and heavy metals into the water through biogeochemical processes, thereby affecting the ecosystem of the reservoir. 
The reservoir sediment (RS) boasts a high utilization value because it is similar to the soil in terms of properties and rich in organic matter and minerals. Harmless treatment and recycling of RS would be environmentally friendly and resource-efficient. As a byproduct of the phosphorus chemical industry, phosphogypsum (PG) has a cumulative stockpile of more than 600 million $t$ but the comprehensive utilization rate is below $40 \%$ [9]. To recycle RS and PG, one of the most important pathways is to prepare them into building materials such as building bricks, lightweight aggregates, and cementing materials [10-14].

Traditional foamed concrete (FC) is a lightweight porous concrete prepared by mixing cementing materials, mineral admixtures, additives, foaming agents, and foam stabilizers at a certain ratio $[15,16]$. The advantages of FC include lightweight, good fluidity, strong thermal insulation, and a wide density range $\left(300-1,850 \mathrm{~kg} \cdot \mathrm{cm}^{-3}\right)$ [17]. This energysaving green material can replace the traditional clay bricks and thereby save land resources [18].

The use of industrial solid waste to prepare FC has been widely used as a way to absorb solid waste. The foam concrete prepared by solid waste has good performance and wide application. FCs are being prepared with various solid wastes as raw materials, such as slag, fly ash, metakaolin, steel slag, and desulfurized gypsum [19-22]. Domestic and foreign scholars have prepared FCs solely from VTs, RS, or PG. However, there is no report on mixture of VTs, RS, and PG to prepare FC. The composition of VTs, RS, and PG differs greatly from country to country and from region to region. Domestically, there is an urgent need to treat these three types of wastes. Therefore, it is necessary to study whether it is feasible to mix the three materials into FC.

Based on the idea of treating waste with waste, this paper carries out experiments on the preparation of FC by mixing VTs, RS, and PG. The aim is to prepare A06 and C3.0 grade FC that meets the requirements of JG/T 266-2011 Foamed Concrete Industry Standard, making it a new type of lightweight wall material with good thermal insulation performance. The use of VTs, RS, and PG to prepare foamed concrete can achieve the high-value utilization of quartz and other minerals in solid waste. It can provide new ways to improve the comprehensive utilization value and utilization rate of solid waste, save land, save resources, and reduce environmental pollution, so as to provide technical support for constructing a circular economy industrial chain in mining areas. It can effectively alleviate the social contradictions and the pressure on the environment and safety caused by solid waste storage in mining enterprises. On the other hand, the preparation of FC insulation materials meets the low carbon and environmental protection development strategy proposed by our government, representing the development direction of the transformation and upgrading of China's construction industry in the future. The physicochemical properties of the raw materials were studied by using X-ray diffraction (XRD), X-ray fluorescence analysis (XRF), and inductively coupled plasma emission spectrometer (ICP-OES). The preparation and properties of FC were investigated by particle size analysis and strength test.
The hydration products and microstructure of FC were analyzed by using XRD, field emission scanning electron microscopy (FE-SEM), and X-ray energy spectrum analysis (EDS). The research results provide theoretical and technical supports to the recycling of VTs, RS, and PG.

\section{Raw Materials and Experimental Method}

\subsection{Raw Materials}

2.1.1. Vanadium Tailings (VTs). The VTs used in our experiments are the waste slag of acidic extraction of vanadium from stone coal, a kind of vanadium ore. The waste slag is black in appearance, acidic, and $2.61 \mathrm{~g} \cdot \mathrm{cm}^{-3}$ in density. From the XRD pattern in Figure 1, it can be observed that the VTs mainly encompass minerals like quartz and orthoclase, plus a few anhydrites and pyrites. The XRF data in Table 1 show that $\mathrm{SiO}_{2}$ is the primary chemical component of the VTs, with a content of $64.21 \%$. About $93.67 \%$ of the VTs can be retained by a $0.08 \mathrm{~mm}$ square hole sieve. For the VTs, the extraction toxicity of heavy metals meets the requirements in the National Standard GB/T 5085.3-2007 Identification Standards for Hazardous Wastes-Identification for Extraction Toxicity (Table 2).

2.1.2. Reservoir Sediment (RS). The RS used in our experiments has a gray surface, fine particles, and a few impurities like water plants. The water content was tested as $70 \%$. The RS was air-dried, stoved, and calcinated at $1,300^{\circ} \mathrm{C}$. The calcined product was quenched with water, stoved, and grinded with a ball mill into the raw material. Tables 1 and 2 show the main chemical components and extraction toxicity of the ground RS, respectively. The ground RS is mainly composed of inorganics, including $\mathrm{SiO}_{2}$ (62.34\%), $\mathrm{Al}_{2} \mathrm{O}_{3}$ (16.41\%), $\quad \mathrm{Fe}_{2} \mathrm{O}_{3}$ (5.29\%), $\mathrm{CaO}+\mathrm{MgO} \quad(10.12 \%)$, and $\mathrm{K}_{2} \mathrm{O}+\mathrm{Na}_{2} \mathrm{O}(3.20 \%)$. The heavy metal contents of $\mathrm{Cu}, \mathrm{Zn}$, $\mathrm{Pb}$, and $\mathrm{Cd}$ meet the requirements in GB/T 5085.3-2007. The ground RS has a specific surface area (SSA) of $522 \mathrm{~m}^{2} \cdot \mathrm{kg}^{-1}$. The mineral components include quartz, mullite, anorthosite, and calcium akermanite (Figure 1(b)). The extraction toxicity of heavy metals meets the requirements in GB/T 5085.3-2007 (Table 2).

2.1.3. Phosphogypsum (PG). Tables 1 and 2 show the main chemical components and extraction toxicity of the PG, respectively. PG exists in the form of gray powders, whose particle size is $5 \mu \mathrm{m} \sim 150 \mu \mathrm{m}$ and relative density is $2.31 \mathrm{~g} \cdot \mathrm{cm}^{-3}$. The main mineral components are $\mathrm{CaSO}_{4} \cdot 2 \mathrm{H}_{2} \mathrm{O}$ and $\mathrm{CaSO}_{4} \cdot 1 / 2 \mathrm{H}_{2} \mathrm{O}$ (Figure $1(\mathrm{c})$ ). The extraction toxicity meets the requirements in the said national standard.

2.1.4. Lime. Table 1 shows the chemical components of lime. The lime can be digested in $14 \mathrm{~min}$ at $67^{\circ} \mathrm{C}$. Less than $15 \%$ can be retained by a $0.08 \mathrm{~mm}$ square hole sieve, which meets the requirements in JC/T 621-2009 Lime for silicate building products. 


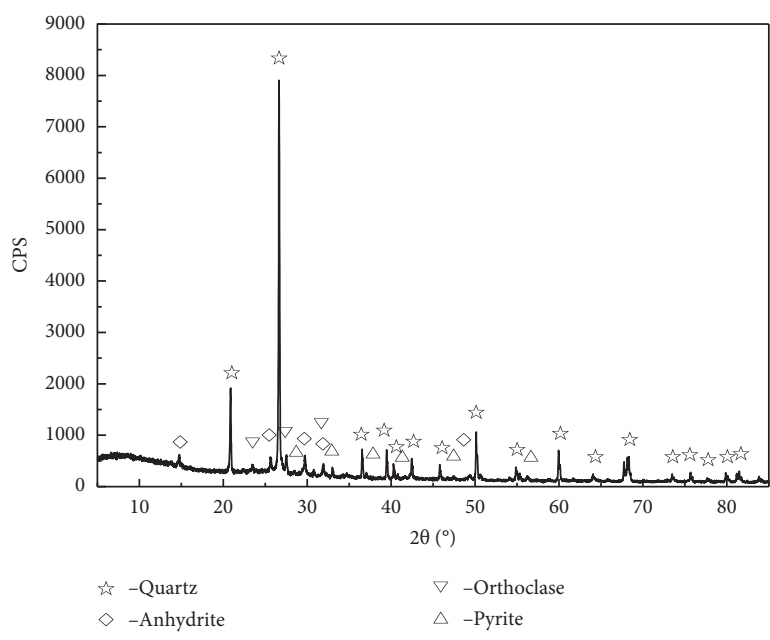

(a)

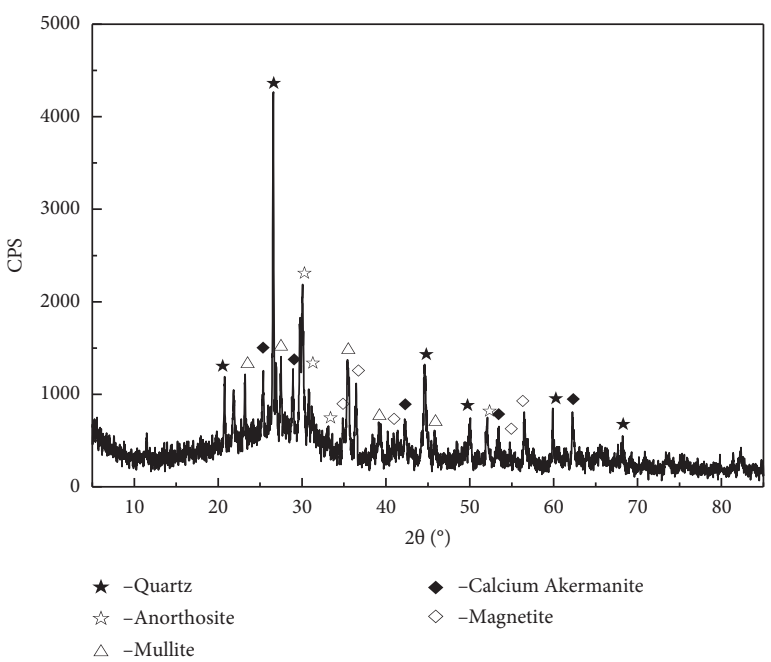

(b)

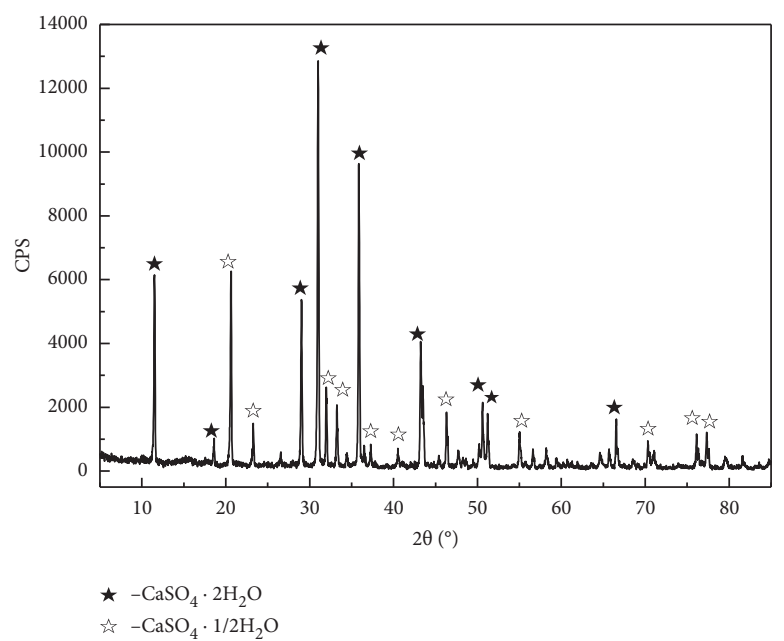

(c)

Figure 1: XRD patterns of raw materials: (a) VTs, (b) RS, and (c) PG.

TABLe 1: Chemical composition of raw materials (wt.\%).

\begin{tabular}{lccccccccrrr}
\hline Materials & $\mathrm{SiO}_{2}$ & $\mathrm{Al}_{2} \mathrm{O}_{3}$ & $\mathrm{CaO}$ & $\mathrm{MgO}$ & $\mathrm{Fe}_{2} \mathrm{O}_{3}$ & $\mathrm{FeO}$ & $\mathrm{Na}_{2} \mathrm{O}$ & $\mathrm{K}_{2} \mathrm{O}$ & $\mathrm{SO}_{3}$ & $\mathrm{P}_{2} \mathrm{O}_{5}$ & $\mathrm{LOI}^{2}$ \\
\hline VTs & 64.21 & 6.41 & 6.60 & 0.37 & 3.53 & 0.07 & 0.13 & 3.20 & 5.39 & 0.04 & 9.46 \\
RS & 62.34 & 16.41 & 6.81 & 3.31 & 5.29 & 0.17 & 0.58 & 2.62 & - & 1.84 & 0.34 \\
PG & 14.57 & 0.13 & 33.72 & 0.17 & 0.15 & 0.02 & - & 0.21 & 45.75 & 0.94 & 4.01 \\
OPC & 22.50 & 4.86 & 66.30 & 0.83 & 3.43 & 0.21 & 0.24 & 0.31 & - & 0.02 & 0.12 \\
Lime & 5.45 & 3.85 & 78.76 & 3.59 & 1.68 & 0.08 & 0.39 & 1.25 & 0.45 & 0.24 & 3.93 \\
\hline
\end{tabular}

TABle 2: Extraction toxicity of raw materials.

\begin{tabular}{lcccccccc}
\hline Materials & $\begin{array}{c}\mathrm{Cu} \\
(\mathrm{mg} / \mathrm{L})\end{array}$ & $\begin{array}{c}\mathrm{Pb} \\
(\mathrm{mg} / \mathrm{L})\end{array}$ & $\begin{array}{c}\mathrm{Zn} \\
(\mathrm{mg} / \mathrm{L})\end{array}$ & $\begin{array}{c}\mathrm{Ni} \\
(\mathrm{mg} / \mathrm{L})\end{array}$ & $\begin{array}{c}\mathrm{Cd} \\
(\mathrm{mg} / \mathrm{L})\end{array}$ & $\begin{array}{c}\mathrm{Cr} \\
(\mathrm{mg} / \mathrm{L})\end{array}$ & $\begin{array}{c}\mathrm{As} \\
(\mathrm{mg} / \mathrm{L})\end{array}$ & $\begin{array}{c}\mathrm{Hg} \\
(\mathrm{mg} / \mathrm{L})\end{array}$ \\
\hline VTS & 0.028 & 0.42 & 0.33 & 0.0009 & 0.0013 & 0.021 & 0.0056 & 0.000021 \\
RS & 39.241 & 0.24 & 56.57 & 0.0165 & 0.13627 & 0.258 & 0.1673 & 0.00336 \\
PGS & 0.925 & 1.84 & 24.63 & 0.0049 & 0.2818 & 2.556 & 0.1873 & 0.06258 \\
Limit value & 100 & 5 & 100 & 5 & 1 & 5 & 5.21 \\
\hline
\end{tabular}


2.1.5. Ordinary Portland Cement (OPC). The PO 42.5 OPC was adopted for our experiments. The chemical components of the OPC are shown in Table 1. The initial and final setting time periods are $118 \mathrm{~min}$ and $190 \mathrm{~min}$, respectively, which are in line with the requirements in GB 175-2007 Ordinary Portland Cement.

2.1.6. Aluminum Powder (AP). The active aluminum content is $88 \%$, the solid content is $77 \%$, and the foaming rate is $91 \%$ in $16 \mathrm{~min}$ and $99 \%$ in $30 \mathrm{~min} .1 .5 \%$ of the AP can be retained by a 200 -mesh sieve. The AP has good water dispersibility and no pellets. Each gram of AP can cover $5,150 \mathrm{~cm}^{2}$ of the water surface if it is arranged continuously as a layer of single particles. The physical properties of the OPC are shown in Table 3.

2.1.7. Other Materials. The foam stabilizer is a specific mixture of oleic acid, triethanolamine, and water at room temperature. After adding the composite foam stabilizer, the suspension performance of $\mathrm{Al}$ powder particles is improved; it is in direct contact with water and the gas generation is smooth. At the same time, due to the high-liquid phase content in the pores, the liquid phase contact area is increased and the gas-liquid mass transfer coefficient and reaction speed are increased; so more hydration products are generated, the hydration products are stacked densely and the cementation ability between particles is enhanced, which plays a great role in improving the compressive strength of FC products.

2.2. Experimental Method. The VTs were dried at $105^{\circ} \mathrm{C}$ in an electro-thermostatic blast drying oven until the water content fell below $0.1 \%$. Then, $5 \mathrm{~kg}$ of VTs sample was weighed and grinded in an $\mathrm{SM} \varphi 500 \mathrm{~mm} \times 500 \mathrm{~mm}$ cement test grinder.

The RS was collected, dewatered through deposition, and air-dried in a cool place indoors. After that, the material was dried at $105^{\circ} \mathrm{C}$ in the oven and calcined in a CD-1700X muffle furnace, with a holding time of $4 \mathrm{~h}$. After calcination, the material was quenched to normal temperature in water. Then, the sample was dried at $105^{\circ} \mathrm{C}$ in the oven until the water content fell below $0.1 \%$ and grinded in the $\mathrm{SM} \varphi 500 \mathrm{~mm} \times 500 \mathrm{~mm}$ cement test grinder.

The PG was collected, screened using an RK/ZS standard sieve shaker, and dried at $105^{\circ} \mathrm{C}$ in the oven until the water content fell below $0.1 \%$. Next, the material was grinded with an agate grinder into powders that can pass through the $-0.074 \mathrm{~mm}$ standard sieve.

The ground VTs, RS, and PG were mixed with lime and OPC by a certain ratio (Table 4). The radioactive indices of the dry mixture meet the requirements in the National Standard GB/T6566-2010 Limits of Radionuclides in building materials (Table 5 ).

Next, $50^{\circ} \mathrm{C}$ warm water was added to the mixture at the water cement ratio of 0.6 , followed by a 90 s-long stirring. Afterward, an amount of AP, equivalent to $0.07 \%$ of the dry mixture, was added, followed by $40 \mathrm{~s}$-long stirring. Then, the mixture was poured, foamed, kept still, demolded, and cured into concrete. The dry density and compressive strength of the test blocks were measured. The casting mold is of the size $100 \mathrm{~mm} \times 100 \mathrm{~mm} \times 100 \mathrm{~mm}$. The foaming, standing, and steam curing lasted for $10 \mathrm{~h}$ at a $55^{\circ} \mathrm{C}$ constant temperature curing box before demolding.

2.3. Sample Testing. The particle size distribution of the ground VTs was measured using an Ms2000 laser particle size analyzer. The SSAs of the ground VTs and RS were captured with a QBE-9 automatic SSA tester.

The dry density, compressive strength, and water absorption of the samples were measured in reference to JG/T 266-2011 Foamed Concrete. The measurement of compressive strength was carried out with a WDW-50 computer control electronic universal testing machine, which meets the provisions for GB/T 2611-2007 General Requirements for Testing Machines: the measuring accuracy of the testing machine should be $\pm 1 \%$; the failure load of samples should be greater than $20 \%$ and smaller than $80 \%$ of the measuring range; and the loading speed should be controlled to $2.0 \mathrm{kN} / \mathrm{s}$.

The chemical composition of raw materials was analyzed with an Axios advanced wavelength dispersive X-ray fluorescence (XRF) spectrometer. The heavy metal contents of the raw materials were analyzed with a Prodigy 7 wholespectrum direct reading inductively coupled plasma emission spectrometer (ICP-OES). The mineral phases of raw materials and FC were analyzed with a Panaco X-ray diffractometer, with the tube voltage of $40 \mathrm{kV}$ and current of $50 \mathrm{~mA}$. The micromorphology of the FC hydration products was observed with a Carl Zeiss SUPRA ${ }^{\mathrm{TM}} 55$ field emission scanning electron microscope.

\section{Experimental Results and Discussion}

3.1. Effect of VTs Fineness on FC Performance. Figure 2 and Table 6 show the particle distributions of VTs powders grinded for different lengths of time. With the extension of grinding time, the general trends are the decline in particle size and the increase of SSA. As the grinding time increased from $30 \mathrm{~min}$ to $60 \mathrm{~min}$, the particle size distribution of VTs is narrowed and gradually converged in the direction of small particle size. As the grinding time increased from $30 \mathrm{~min}$ to $60 \mathrm{~min}$, the $D_{10}$ of VTs powder dropped from $2.725 \mu \mathrm{m}$ to $1.524 \mu \mathrm{m}$, i.e., the characteristic particle size reduced by $44.1 \%$; $D_{50}$ dropped from $25.803 \mu \mathrm{m}$ to $7.852 \mu \mathrm{m}$, i.e., the characteristic particle size reduced by $70.1 \%$; and $D_{90}$ dropped from $104.450 \mu \mathrm{m}$ to $34.209 \mu \mathrm{m}$, i.e., the characteristic particle size reduced by $67.3 \%$. At $50 \mathrm{~min}$ and $60 \mathrm{~min}$, the SSAs were $768 \mathrm{~m}^{2} \cdot \mathrm{kg}^{-1}$ and $796 \mathrm{~m}^{2} \cdot \mathrm{kg}^{-1}$, respectively, the growth of SSA slowed down, and the grinding efficiency dropped. It is not very meaningful to increase the SSA of VTs by further extending the grinding time. Hence, during the early phase of grinding, the VTs particles mainly went through size reduction. With the increase of fineness, the speed of size reduction slowed down. Once the grinding time reached a threshold, further grinding led to the equilibrium 


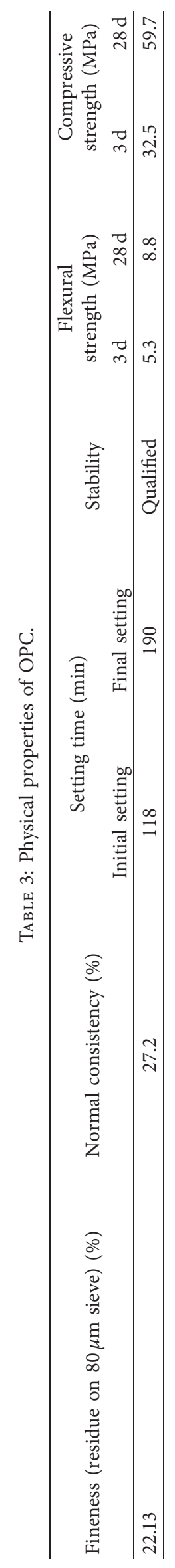


TABLE 4: Mixing ratio of our experiments.

\begin{tabular}{lccccccc}
\hline \multirow{2}{*}{ Serial number } & \multicolumn{5}{c}{ Mixing ratio of dry materials (\%) } & Water cement ratio & $\begin{array}{c}\text { Foaming agent } \\
\text { AP (\%) }\end{array}$ \\
& VTs & RS & Lime & OPC & PG & & \\
Dry mixture (\%)
\end{tabular}

TABLE 5: Radioactive test results of FC mixture.

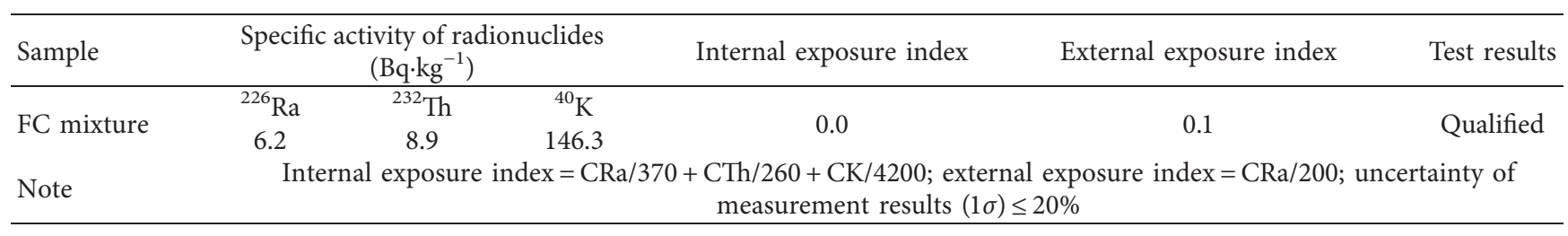

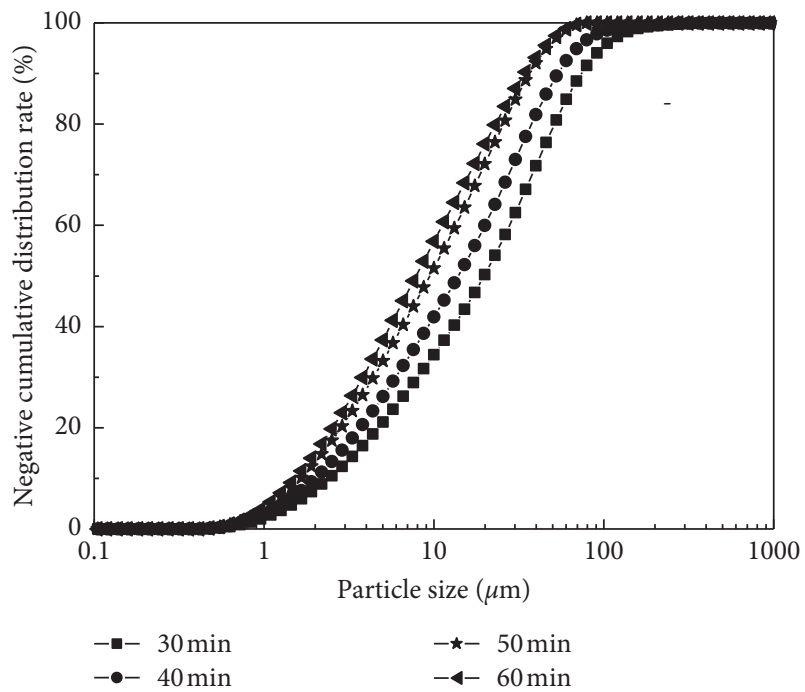

Figure 2: Particle size distributions of VTs at different grinding time periods.

state, under which the particle size was no longer reduced and the particles even clustered together.

Figure 3 records the effect of fineness on VTs activity. During the experiments, VTs powders of different SSAs (content: 30\%) were mixed with PO 42.5 OPC. According to the GB/T 12957-2005 Test method for activity of industrial waste slag used as addition to cement, the $28 \mathrm{~d}$ compressive strength rate of cement mortar was calculated (activity index $R_{28}$ ). Figure 3 shows the activity index of the ground VTs. It can be observed that, with the increase of SSA, the activity index of the VTs initially declined, reached the valley at the SSA of $475 \mathrm{~m}^{2} \cdot \mathrm{kg}^{-1}$, and then gradually rebounded. When the SSA increased to $475 \mathrm{~m}^{2} \cdot \mathrm{kg}^{-1}$, the activity index of the VTs peaked at $70.7 \%$, presenting an inflection point. In this case, the SSA increase has little promoting effect on VTs activity. This is consistent with the particle size variation of VTs.
3.2. Effect of VTs Content on FC Performance. Figure 4 shows the effect of different VTs contents on the physical performance of FC. The $28 \mathrm{~d}$ compressive strength of FC increased first and then decreased, with the growing content of VTs. When the VTs content was $40 \%$, the compressive strength of FC reached $3.56 \mathrm{MPa}$ and the oven-dry density was $619.1 \mathrm{~kg} \cdot \mathrm{m}^{-3}$, which satisfy the requirements of JG/T 266-2011 on A06 and C3.0 FC. With the growing content of VTs, the strength of FC started to decline; meanwhile, the oven-dry density of FC gradually increased. At the VTs content of $30 \%$, oven-dry density stood at $596.4 \mathrm{~kg} \cdot \mathrm{m}^{-3}$; when the VTs content rose to $50 \%$, the over-dry density climbed up to $652.5 \mathrm{~kg} \cdot \mathrm{m}^{-3}$. The main reason may be that the content of VTs in the D1 sample of FC is low, the content of active $\mathrm{SiO}_{2}$ in the raw material system is low, and there are few hydration products produced by active $\mathrm{SiO}_{2}$ and $\mathrm{Ca}(\mathrm{OH})_{2}$ in slurry, resulting in too large pores formed by aluminum powder gas generation in the D1 sample and lowdry density and compressive strength of the sample [23]. When the VTs content reached 50\%, all the pores of FC were filled up, resulting in the peak oven-dry density. However, under a constant water cement ratio, further growth in VTs content pushed up the consistency of the slurry, dragging down the overall fluidity. During the foaming process, some of the air cannot be released. Hence, the foaming height failed to meet the requirements, leading to a poor visual effect of the FC. To make full use of the VTs, the VTs content was determined as $40 \%$ from the perspectives of economy and performance (Table 4 ).

\subsection{Phase Analysis of FC}

3.3.1. XRD Analysis. Figure 5 displays the $\mathrm{XRD}$ patterns of D3 FC samples cured for $3 \mathrm{~h}, 3 \mathrm{~d}, 7 \mathrm{~d}$, and $28 \mathrm{~d}$, respectively. The variation in curing time led to changes in the hydration products of FC. Compared with Figure 1, the 1d curve in Figure 5 contained the characteristic peaks of quartz and orthoclase; the diffraction peak of AFt was not observed, indicating that the hydration reaction had not taken place 
TABLE 6: Characteristic particle size distributions and SSAs of VTs at different grinding time periods.

\begin{tabular}{lcccc}
\hline \multirow{2}{*}{ Characteristic particle size } & \multicolumn{3}{c}{ Grinding time (min) } \\
& 30 & 40 & 50 & 60 \\
\hline$D_{10}$ & 2.412 & 2.004 & 1.648 & 7.524 \\
$D_{50}$ & 19.793 & 13.902 & 9.466 & 7.852 \\
$D_{90}$ & 73.909 & 53.526 & 34.577 & 34.209 \\
SSA $\left(\mathrm{m}^{2} \cdot \mathrm{kg}^{-1}\right)$ & 475 & 600 & 768 & 796 \\
\hline
\end{tabular}

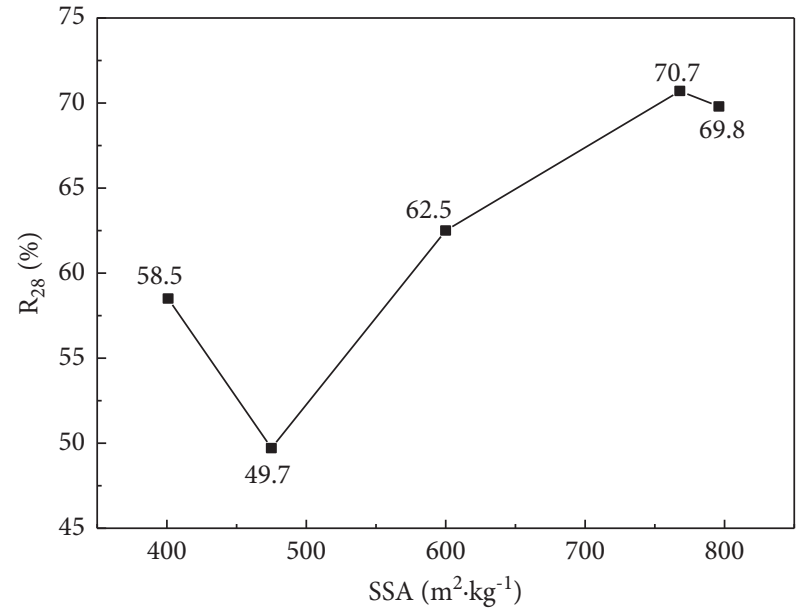

FIGURE 3: Effect of fineness on VTs activity.

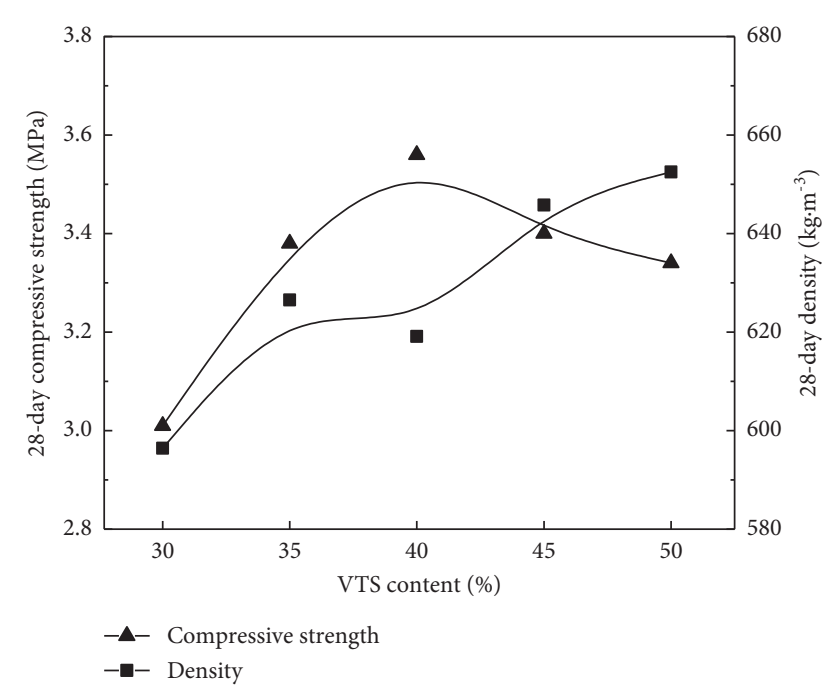

Figure 4: Effect of VTs content on FC performance.

yet. With the growth of curing time, the diffraction peaks of all mineral phases started to decline, while the diffraction peak of AFt, a hydration product, came into being. This is because the cement is hydrated during standard curing and the active particles in the raw materials start to react with $\mathrm{Ca}(\mathrm{OH})_{2}$, the digestion product of $\mathrm{CA}$, producing hydration products of C-S-H gel and C-A-H crystal; in the presence of $\mathrm{PG}$, the $\mathrm{Ca}^{2+}$ and $\mathrm{SO}_{4}{ }^{2-}$ released by $\mathrm{PG}$ react with the $\mathrm{OH}^{-}$ and $\mathrm{AlO}^{2-}$ in the slurry and the product $\mathrm{C}-\mathrm{A}-\mathrm{H}$ will quickly form the AFt crystal [24]. As can be seen in the XRD patterns of $3 \mathrm{~d}, 7 \mathrm{~d}$, and $28 \mathrm{~d}$, the diffraction peak of gypsum gradually weakened and the diffraction peak of the AFt crystal was enhanced with the extension of curing time. Besides, steamed bun-shaped peaks appeared at $25^{\circ}-35^{\circ}$. The reason is that the diffraction peaks are widened due to the production of hydration products with indefinite form and poor crystallization capacity and the presence of small-to-medium particles in FC [25]. The gradual formation of hydration products AFt and C-S-H gel in the early phase of sample curing is the primary cause for the hardening of FC blocks. The accumulation of these products facilitates the strength enhancement of FC in the late phase. Among the phases of FC, calcite appears through carbonization during the preparation and curing processes. In the raw material system, there is a low presence of pyrite of the original VTs. That is why no diffraction peak of pyrite was observed in the XRD patterns. After $28 \mathrm{~d}$ of standard curing, quartz and orthoclase still existed, but their diffraction peaks were weakened. It can be preliminarily concluded that these minerals have not fully reacted under the conditions of standard curing [26]. The residual quartz, mullite, orthoclase, calcite, pyrite, and PG of the raw materials partly remain in the FC products as aggregates.

3.3.2. SEM Analysis. Several samples were prepared from D3 FCs cured for $1 \mathrm{~d}, 3 \mathrm{~d}, 7 \mathrm{~d}$, and $28 \mathrm{~d}$ and subjected to the SEM analysis (zoom in 10000 times). The analysis results of these samples are given in Figures 6-8. Specifically, Figure 6 provides the SEM images of cross-sectional pores in $1 \mathrm{~d}, 3 \mathrm{~d}$, $7 \mathrm{~d}$, and $28 \mathrm{~d}$ FCs; Figure 7 displays the SEM-EDS images of the hydration products of $7 \mathrm{~d}$ FC; Figure 8 presents the SEM images inside the pores of $3 \mathrm{~d}$ and $28 \mathrm{~d}$ FCs.

As shown in Figure 6, the cross-sectional pores of FC provide sufficient space for crystal growth. As a result, with the growth of curing time, more and more crystals are formed and the crystal morphology became increasingly regular. On the surface of the $1 \mathrm{~d} \mathrm{FC}$, flocculated aggregates were scattered, which are probably the aggregation of gelatinous tobermorite and rod-shaped AFt crystals [27]. The flocculated aggregates gradually increased in the $3 \mathrm{~d}$ FC. On the $7^{\text {th }}$ day of curing, the rod-shaped crystals grew along the cross section, were extended in length, and were

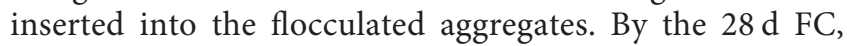
rod-shaped crystals, through centralized growth, basically covered up the cross-sectional pores, forming crystal aggregates that enhance the support to pore walls [28]. The morphological change of aggregates was apparent in the SEM image enlarged by 10,000 times. In the $1 \mathrm{~d}$ FC (Figure 6(a)), the aggregates dispersed on the pore walls and the rod-like crystals were attached to the gel surface; in 


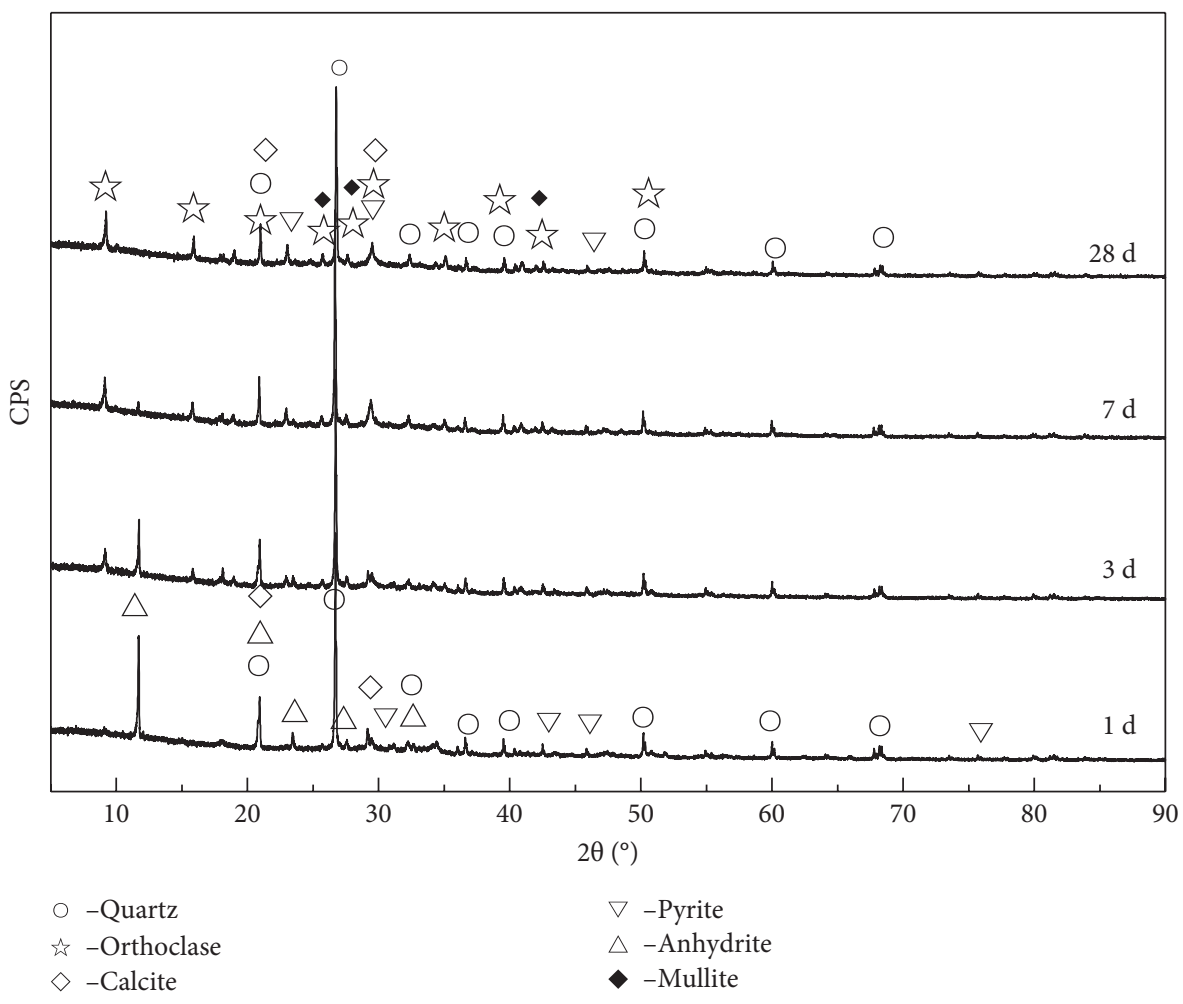

FIGURE 5: XRD patterns of FC at different curing ages.
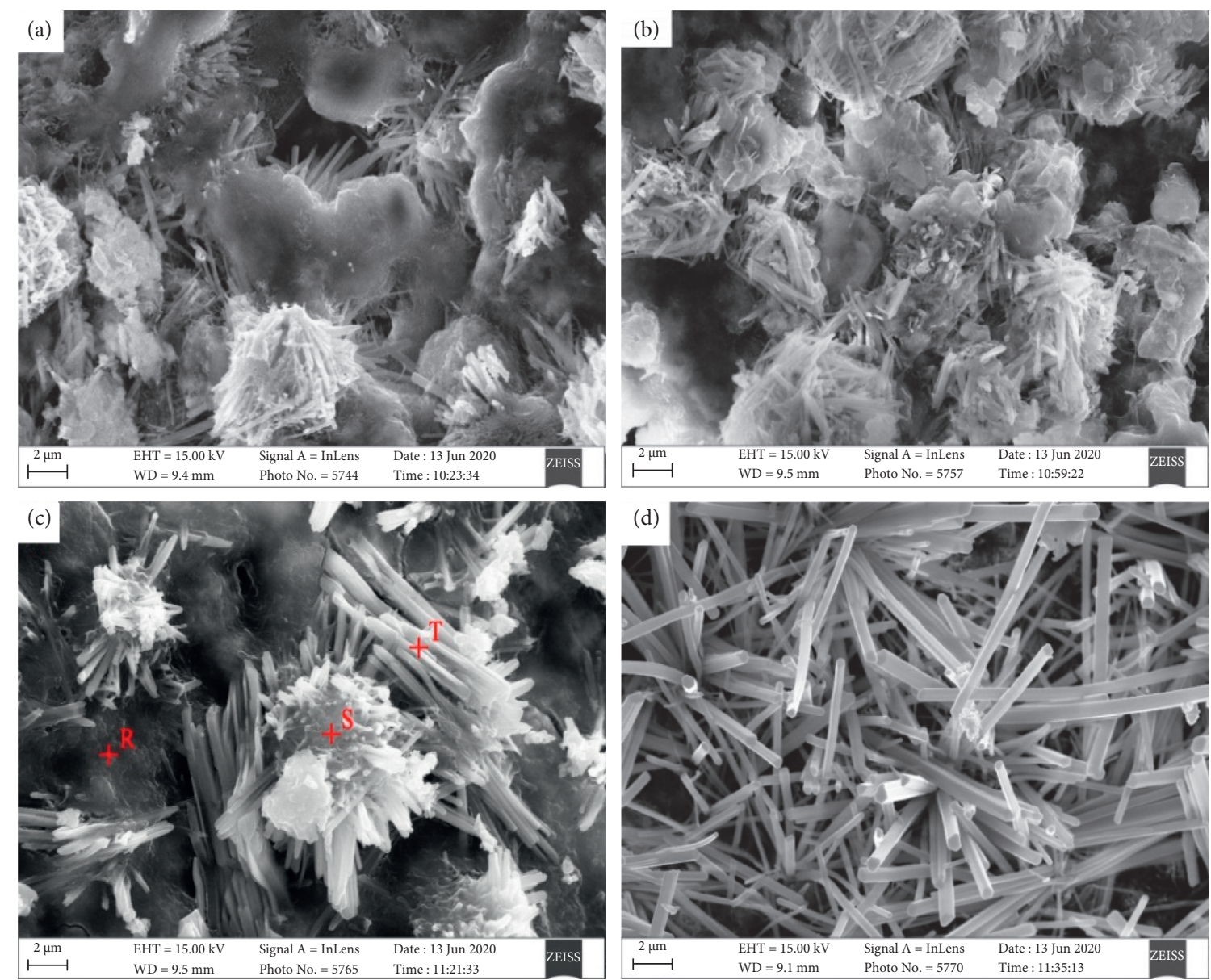

Figure 6: SEM images of cross-sectional pores of FC at different ages (zoom in 10000 times). (a) $1 \mathrm{~d}$, (b) $3 \mathrm{~d}$, (c) $7 \mathrm{~d}$, and (d) $28 \mathrm{~d}$. 

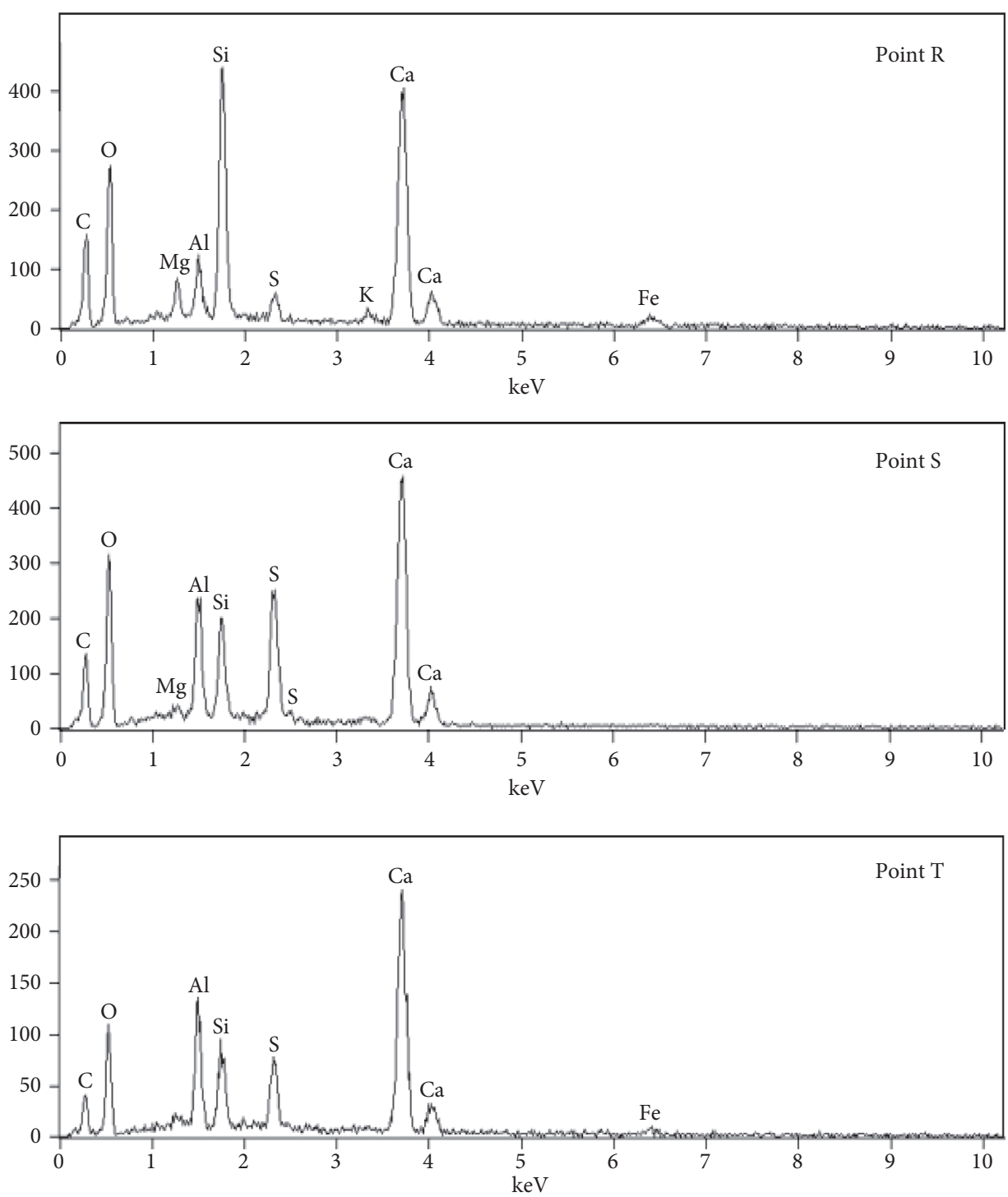

FIGURE 7: SEM-EDS images of hydration products in Figure 6(c).
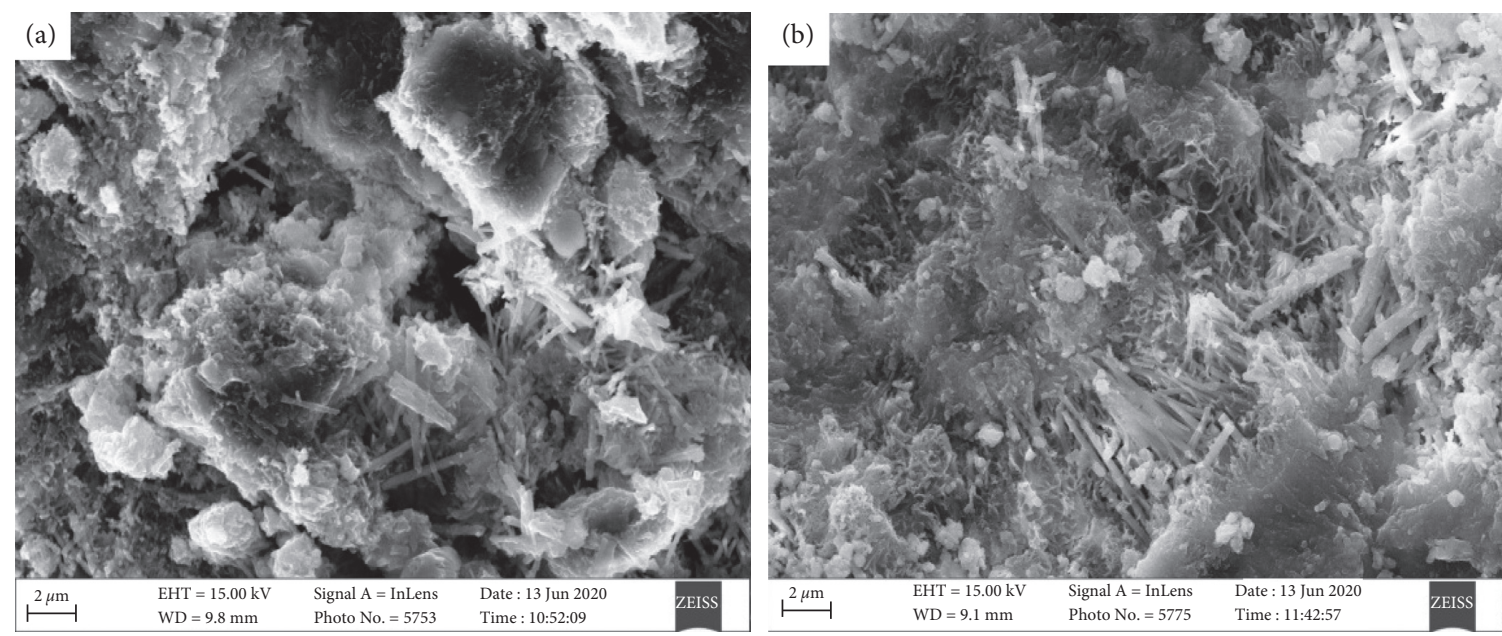

FIGURE 8: SEM images inside the pores of FC at different ages (zoom in 10000 times). (a) $3 \mathrm{~d}$. (b) $28 \mathrm{~d}$. 
the $3 \mathrm{~d}$ FC (Figure 6(b)), there were more such aggregates, which almost cover up the cross-sectional pores; in the $7 \mathrm{~d}$ FC (Figure 6(c)), the rod-like crystals in the aggregates grew longitudinally, the gelatinous substances gradually decreased, and the said crystals became more prominent and were inserted into the aggregates. From the SEM-EDS images on the hydration products of $7 \mathrm{~d} \mathrm{FC}$, it can be inferred that the gelatinous substance at point $R$ is C-S-H gel, that at point $T$ is AFt, and that at point $S$ is the gelatinous substance mixed with AFt-crystallization nuclei. These phenomena agree well with the XRD analysis. As the curing age increased to $28 \mathrm{~d}$ (Figure 6(d)), the hydration reaction continued and the hydration products were crystallized to a much higher degree; the AFt crystals became thicker and crisscrossed the entire cross-sectional pores. The interconnected crystals formed a network, making the system denser. The network can alter the pore structure of FC and reduce the concentration of external stress. This helps to enhance the compressive strength of FC and improve the thermal insulation and heat preservation capacity of FC [29].

As shown in Figure 8, the cross section inside the pores of FC is too small for crystal growth. Most crystals developed in capillary pores, which greatly increased the structural density of pore walls. With the extension of curing time, the number of rod-like crystals was on the rise. From the images of $3 \mathrm{~d}$ and $28 \mathrm{~d}$ FCs (magnified by 10,000 times), there were clear pores in the $3 \mathrm{~d}$ FC (Figure $8(\mathrm{a})$ ); by contrast, the pores in the $28 \mathrm{~d}$ FC (Figure 8 (b)) were basically filled up by the cross-growing rod-like crystals; the enhanced density enables the pore walls to resist greater pressure from the outside (Figure 8(b)).

\section{Conclusions}

(1) From raw materials like VTs, RS, and PG, this paper successfully prepares the A06 and C3.0 FC, which meets the strength required by the industry standard JG/T 266-2011. The total utilization rate of solid waste is as high as $82 \%$. This is positive for expanding the sources of raw materials for FC, promoting the comprehensive use of solid waste, and protecting the environment.

(2) When the SSA of VTs is $768 \mathrm{~m}^{2} \cdot \mathrm{kg}^{-1}$, the mass ratio of materials of VTs is $40 \%$, RS $34 \%$, CA $5 \%$, OPC $13 \%$, PG $8 \%$, and an amount of AP equivalent to $0.07 \%$ of the total weight of the dry mixture; the water cement ratio is 0.6 ; the water temperature is $50^{\circ} \mathrm{C}$; the curing temperature is $55^{\circ} \mathrm{C}$; the compressive strength of FC sample is $3.56 \mathrm{MPa}$; and the ovendry density is $619.1 \mathrm{~kg} \cdot \mathrm{m}^{-3}$.

(3) XRD and SEM analyses show that, under standard curing conditions, the hydration of FC mainly produces C-S-H gel and AFt; calcite appears through carbonization during the preparation and curing processes; and the residual quartz, mullite, orthoclase, calcite, pyrite, and PG of the raw materials partly remain in the FC products as aggregates.

\section{Data Availability}

The data used to support the findings of this study are available from the corresponding author upon request.

\section{Conflicts of Interest}

The authors declare that they have no conflicts of interest.

\section{Acknowledgments}

The authors gratefully acknowledge the financial supports from the National Key Research and Development Program of China (No. 2018YFC1903602-01), Natural Science Foundation of Hebei Province (No. E2020402079), Science and Technology Research Project of Higher Education Institutions in Hebei Province (No. ZD2016014), Shaanxi Key Laboratory of Comprehensive Utilization of Tailings Resources (No. 2017SKY-WK008), State Key Laboratory of Solid Waste Reuse for Building Materials (No. SWR-2020004), Science and Technology Research and Development Plan of China Railway Construction Group Co., Ltd. (Nos. 20-02a and 21-13b), and Hebei Graduate Innovation Funding Project (No. CXZZSS2021091).

\section{References}

[1] C. Ren, K. Li, W. Ni, and S. Zhang, "Preparation of mine filling material from steel slag mud," Annales de Chimie Science des Matériaux, vol. 43, no. 4, pp. 217-224, 2019.

[2] W. Wang, P. Ye, X. Zhou et al., "Effects of reductant type on coal-based direct reduction of iron ore tailings," Annales de Chimie Science des Matériaux, vol. 42, no. 3, pp. 453-466, 2018.

[3] B. Wei, Y. Zhang, and S. Bao, "Preparation of geopolymers from vanadium tailings by mechanical activation," Construction and Building Materials, vol. 145, pp. 236-242, 2017.

[4] J. Alcalde, U. Kelm, and D. Vergara, "Historical assessment of metal recovery potential from old mine tailings: a study case for porphyry copper tailings, Chile," Minerals Engineering, vol. 127, pp. 334-338, 2018.

[5] H. Lu, C. Qi, Q. Chen, D. Gan, Z. Xue, and Y. Hu, "A new procedure for recycling waste tailings as cemented paste backfill to underground stopes and open pits," Journal of Cleaner Production, vol. 188, pp. 601-612, 2018.

[6] X. Wang, R. Yu, Z. Shui et al., "Development of a novel cleaner construction product: ultra-high performance concrete incorporating lead-zinc tailings," Journal of Cleaner Production, vol. 196, pp. 172-182, 2018.

[7] C.-l. Wang, W. Ni, S.-q. Zhang, S. Wang, G.-s. Gai, and W.-k. Wang, "Preparation and properties of autoclaved aerated concrete using coal gangue and iron ore tailings," Construction and Building Materials, vol. 104, pp. 109-115, 2016.

[8] C. Wang, G. Zhao, Y. Zheng, K. Zhang, P. Ye, and X. Cui, "Study on the preparation of high performance concrete using steel slag and iron ore tail-ings," Journal of New Materials for Electrochemical Systems, vol. 22, no. 4, pp. 217-223, 2019.

[9] L.-L. Zeng, X. Bian, L. Zhao, Y.-J. Wang, and Z.-S. Hong, "Effect of phosphogypsum on physiochemical and mechanical behaviour of cement stabilized dredged soil from Fuzhou, China," Geomechanics for Energy and the Environment, vol. 25, Article ID 100195, 2021. 
[10] Y. Huang, J. Qian, X. Kang et al., "Belite-calcium sulfoaluminate cement prepared with phosphogypsum: influence of $\mathrm{P} 2 \mathrm{O} 5$ and $\mathrm{F}$ on the clinker formation and cement performances," Construction and Building Materials, vol. 203, pp. 432-442, 2019.

[11] N. Junakova and J. Junak, "Sustainable use of reservoir sediment through partial application in building material," Sustainability, vol. 9, no. 5, pp. 852-864, 2017.

[12] H.-H. Liang and J.-L. Li, "The influence of hydration and swelling properties of gypsum on the preparation of lightweight brick using water supply reservoir sediment," Construction and Building Materials, vol. 94, pp. 691-700, 2015.

[13] Y. Lei, Q. W. Zhu, H. X. Chen, and M. M. Wang, "Development and application of phosphgypsun in plasterboard," Materials Sciences, vol. 9, no. 1, pp. 69-78, 2019.

[14] M. D. Syczewski, A. Borkowski, A. Gąsiński et al., "Phosphogypsum and clay mineral/phosphogypsum ceramic composites as useful adsorbents for uranium uptake," Applied Geochemistry, vol. 123, p. 104793, 2020.

[15] X. Liang, C. Wang, J. Zhan, X. Cui, and Z. Ren, "Study on preparation of eco-friendly autoclaved aerated concrete from low silicon and high iron ore tailings," Journal of New Materials for Electrochemical Systems, vol. 22, no. 4, pp. 224-230, 2019.

[16] Y. Sun, P. Gao, F. Geng, H. Li, L. Zhang, and H. Liu, "Thermal conductivity and mechanical properties of porous concrete materials," Materials Letters, vol. 209, pp. 349-352, 2017.

[17] M. Siva, K. Ramamurthy, and R. Dhamodharan, "Development of a green foaming agent and its performance evaluation," Cement and Concrete Composites, vol. 80, pp. 245-257, 2017.

[18] D. Falliano, D. De Domenico, G. Ricciardi, and E. Gugliandolo, "Experimental investigation on the compressive strength of foamed concrete: effect of curing conditions, cement type, foaming agent and dry density," Construction and Building Materials, vol. 165, pp. 735-749, 2018.

[19] Y. N. Dhoble and S. Ahmed, "Review on the innovative uses of steel slag for waste minimization," Journal of Material Cycles and Waste Management, vol. 20, no. 3, pp. 1373-1382, 2018.

[20] B. Park and Y. C. Choi, "Investigation of carbon-capture property of foam concrete using stainless steel AOD slag," Journal of Cleaner Production, vol. 288, Article ID 125621, 2021.

[21] H. S. Gökçe, D. Hatungimana, and K. Ramyar, "Effect of fly ash and silica fume on hardened properties of foam concrete," Construction and Building Materials, vol. 194, pp. 1-11, 2019.

[22] G. Samson, A. Phelipot-MardeléL, and C. Lanos, "Thermal and mechanical properties of gypsum-cement foam concrete: effects of surfactant," European Journal of Environmental and Civil Engineering, vol. 21, no. 12, pp. 1502-1521, 2017.

[23] P. P. Li, Q. L. Yu, and H. J. H. Brouwers, "Effect of coarse basalt aggregates on the properties of Ultra-high Performance Concrete (UHPC)," Construction and Building Materials, vol. 170, pp. 649-659, 2018.

[24] J. Li, Z. Wang, K. Zhang, C. Wang, and X. Cui, "Properties and hydration mechanism of autoclaved aerated concrete containing coal gangue and fly ash," Journal of New Materials for Electrochemical Systems, vol. 22, no. 4, pp. 231-238, 2019.

[25] J. Bensted and P. Barnes, Structure and Performance of Cements, Spon Press, New York, NY, USA, 2002.

[26] C. Wang, Z. Liu, J. Li, S. Jiao, and Y. Zhang, "Study on preparation of autoclaved aerated concrete using lead-Zinc tailings," Chemical Engineering Transactions, vol. 62, pp. 931-936, 2017.

[27] X. Huang, Z. Wang, Y. Liu, W. Hu, and W. Ni, "On the use of blast furnace slag and steel slag in the preparation of green artificial reef concrete," Construction and Building Materials, vol. 112, pp. 241-246, 2016.

[28] C. Angulski da Luz and R. D. Hooton, "Influence of curing temperature on the process of hydration of supersulfated cements at early age," Cement and Concrete Research, vol. 77, pp. 69-75, 2015.

[29] X. W. Cui, W. Ni, and C. Ren, "Hydration mechanism of all solid waste cementitious materials based on steel slag and blast furnace slag," Chinese Journal of Materials Research, vol. 31, no. 9, pp. 687-694, 2017. 